\title{
Supportive mechanisms for redundant employees in the context of digital transformation of the Russian labour market
}

\author{
Liliya Babynina $^{1,{ }^{*}, \text { Larisa } \text { Kartashova }^{1}, \text { Natalia } \text { Loktyukhina }^{2}, \text { Evgeniya } \text { Shubenkova }}{ }^{1}$, and \\ Olga Nikonova ${ }^{1}$ \\ ${ }^{1}$ Plekhanov Russian University of Economics (PRUE), Moscow, Russia \\ ${ }^{2}$ Financial Research Institute, Moscow, Russia
}

\begin{abstract}
The article presents results of the analysis of the current mechanism for supporting redundant employees with the development of digital transformation processes in the Russian labour market. Three directions for improving this mechanism have been identified: the choice of criteria for the release of personnel, the implementation of an active employment policy and a system of social support for the unemployed. The redundant employees are labour resources and the potential for the development of the country, therefore, it is important not only government support for such employees, but also additional measures of socially responsible employers.
\end{abstract}

\section{Introduction}

In the context of market-oriented economy, the release of employees (reduction in the number or staff of employees) is due to competition, crises in the development of the company and the search for the most profitable business areas. The existing mechanism for supporting redundant workers in Russia have based on labour legislation, as well as on additional initiative measures of socially responsible employers. To implement the system of national projects in the Russian Federation, adopted to achieve new strategic goals of national development, state programs and subprograms have been develop that provide for measures of an active employment policy. They are aimed at improving the system of social support for the unemployed, retraining, raising the qualifications of enterprise employees modernizing the employment infrastructure in the constituent entities of the Russian Federation, improving the work of the state service to support released workers and unemployed citizens, developing the competencies of employees of the employment service.

In the context of a tense demographic situation in Russia with an aging population and a declining birth rate, redundant employees are labour resources and the potential for the development of the country not only among people of working age, but also among pensioners. In this case, we are talking about a large category of citizens in the labour

\footnotetext{
* Corresponding author: Babynina.LS@rea.ru
} 
market. In 2020, they left their previous place of work due to layoffs, personnel cuts, liquidation of an enterprises; own business, 856 thousand people, or almost $20 \%$ of 4.3 million unemployed (in 2019 - 530 thousand people or $20.2 \%$ of 2.6 million unemployed). In the period from January 2020 to June 2021, the highest share of the unemployed was observe in the age groups 20-39 years old [1]. Youth unemployment negatively affects the socio-psychological development of young people, leads to a reorientation or degradation of labour values and to the disappearance of the view of work as a means of personal selfrealization, and is also a significant limitation of the implementation of the country's labour and intellectual potential [2]. Thus, the task of improving the mechanism for supporting redundant personnel in the context of the digital transformation of the Russian labour market seems extremely urgent. In this regard, the authors consider it important to present an analysis of the existing challenges of state policy in this direction and formulate proposals for their solution.

\section{Materials and methods}

The authors have relied for preparing the article on the following materials and research: the results of in-depth interviews with employees of the employment service of the Ryazan region, conducted in 2021 as part of the research work on the topic "Digitalization of the labour market and employment in Russia: trends and development mechanisms", funded from funds of the Federal State Budgetary Educational Institution of Higher Education "Plekhanov Russian University of Economics "(Order No. 867 dated June 28, 2021); the results of expert discussions and surveys of the heads of employment services of the regions of the central federal district in the framework of the study "Organizational and financial mechanisms for supporting the employment of the population in 2021-2023, aimed at reducing the unemployment rate", carried out by the Research Institute for Basic Research on the state order of the Ministry of Finance of Russia (092-00001-21 -00).

As the initial data, the authors used the official statistics of Rosstat, information on the registered labour market provided by the Ministry of Labour of Russia, reports of the International Labour Organization and the Eurofund, population surveys conducted in connection with the scaling of new forms of employment.

Empirical methods based on the analysis of scientific foreign and Russian literature are used. Field studies, a combination of quantitative and qualitative analysis methods, online surveys, personal and telephone interviews were carry out to assess the challenges and opportunities for transforming the employment service of the Russian Federation to support laid-off workers and unemployed citizens.

\section{Results and discussion}

\subsection{Selection criteria for applicants for redundancy}

Studies show that if staff reductions cannot be avoid and all alternatives and opportunities to stimulate the voluntary departure of employees from the enterprise have been exhaust already, the problem arises of the socio - economic justification of measures for forced staff layoffs. At the same time, not enough attention is pay to measures to support employees who remain to work at the enterprise, which reduces the effectiveness of the work carried out to optimize the number of personnel. Not enough attention was pay to the fact that during the period of staff reduction, the support of employees of the human resource management services of the enterprise from the top management is also required to determine the criteria for selecting candidates for the release. The issue of choosing the 
selection criteria for applicants for release requires careful substantiation from the standpoint of economic feasibility and social justice. In this case, two approaches can be use. The first is to leave those who will find it most difficult to gain a new job. The second approach, which has recently become prevailing, is to keep the most qualified workers capable of quickly restructuring and retraining in accordance with new tasks. In the first case, the main criteria will be work experience, age, marital status, health status, in the second, versatile experience and multifunctional skills, qualifications, work efficiency [3].

\subsection{Implementation of an active employment policy}

The results of the analysis of the mechanism for the redundancy of personnel in modern conditions showed that it is based on labour legislation and is implemented within the framework of the state program of the Russian Federation "Promotion of employment of the population", in particular, its subprogram "Active employment policy and social support for unemployed citizens." In fact, almost all the activities of the subprogram aimed at unemployed citizens, and the redundant personnel, who are potentially in the labour market from the moment they receive notification of the upcoming reduction, are actually have not embraced by an active employment policy, which provides for the development of labour mobility of the population. The legislative initiation of the expansion of participants in active employment programs was reflected in the draft law prepared by the Ministry of Labour of Russia [5], which proposes to involve in such programs not only registered unemployed. The citizens registers in employment services as job seekers, and ready to relocate temporarily or relocate for employment for permanent residence in another locality. However, in this case, according to the authors, it is required to assess the possibility of employers' abuse of use of labour mobility programs for the movement of personnel.

Additional measures aimed at reducing tensions in the labour market of the constituent entities of the Russian Federation have developed and implemented by the Government of the Russian Federation. Those measures use during economic crises and sanctions, for support the employment on the North Caucasus, due to restrictions to the COVID-19 pandemic and due to consequences of the pandemic. The additional measures that provide support to enterprises and redundant personnel, such as advanced training of those who are under the threat of dismissal, subsidizing wages, internships, equipping jobs for people with disabilities, etc. However, traditional active employment programs, the list of which have established by Article 7.1 of the Employment Law and additional measures, do not form a single system. The main disadvantages of additional measures are associated with the lack of open reviews and feedback, the ability to assess the long-term effect of their implementation. It is difficult to determine whether the training is formal, whether the competitiveness of the personnel is increasing, whether the business is satisfied with the results of the implementation of these programs.

Since 2012, the implementation of active employment policy measures within the framework of the "Employment Promotion" state program have been transferrin to the regional level and are finance from regional budgets. Under these conditions, the federal list of active employment programs should not be mandatory, but recommendatory. Therefore, the region, based on the situation on the labour market, the specifics of job seekers, available jobs, should itself determine which programs it is preferable to implement.

Thus, we see the improvement of the organization of work with redundant personnel within the framework of an active employment policy in additional measures of labour mobility of redundant workers and in providing the region with greater flexibility in the implementation of such programs. 


\subsection{Problems with the payment of unemployment benefits}

The analysis of social support for the unemployed in the payment of unemployment benefits, carried out by the authors, made it possible to note the following. The allowance has become an analogue of social assistance, having lost its connection with the parameters of the previous job and the unemployed earnings. During the COVID-19 pandemic, when unemployment benefits were increase in 2020, it became a key regulator of the registered labour market. As a result, for the first time, the indicators of actual and registered unemployment came close, since the increase on the amount of the benefit stimulated the population, including those working informally or long-term unemployed, to contact the employment services. The number of recipients of unemployment benefits since the beginning of the pandemic has grown fivefold - from 720 thousand to 3.5 million people [1]. According to the Ministry of Labour of Russia: "With the possibility of receiving benefits in an increased amount, including payments for underage children, citizens, in most cases, did not show interest in receiving services to assist in finding a suitable job. The main goal of a fairly significant part of appeals to the employment service was not employment, but receiving unemployment benefits" 4]. Some citizens receive unemployment benefits fraudulently when they work informally and have an unofficial income. The motivation for this behavior is not so much the benefit itself as the benefits. In particular, an unemployed person, due to the small amount of the benefit or after the termination of its payment, can expect the provision of compensation for the costs of housing and utilities services.

Some unemployed are "professional unemployed" who have been registered with the employment service for a long time, receive benefits and other services. Among of them there are both those who receive benefits fraudulently, and the unemployed who are not motivated to find a job, for example, leading a household. The challenges faced by the employment service and which it will have to overcome are related to the fact that at present its role begins to be reduced mainly to the payment of benefits to "indiscriminate". Determining exact amount benefits for the unemployed and informally employed appears to be a difficult task today. Employers are not interested in cooperation with the employment service for fear of hiring unmotivated applicants. The current situation does not allow the employment service to work fully with motivated job seekers, including laid-off workers and citizens who are experiencing difficulties in finding a job.

At the same time, the is task of supporting the form of social payments for the period of unemployment, highlighted for those who are left really without means of subsistence and to aim for finding employment. In this regard, the authors propose to change the concept of social protection against unemployment - to abolish unemployment benefits and introduce a universal poverty benefit, the concept of which was developed by the FRI in 2015 [6]. The concept of a universal poverty benefit based on the idea of reducing small and large risks of poverty, implemented through the mechanisms of providing job search services to the unemployed and social support for low-income citizens who have lost their jobs. The amount of the allowance should ensure the minimum possible standard of living for a low-income unemployed person and his household for the period of job search.

This proposal deserves a special study, since the opinions of scientists and practitioners do not find unanimous support [7]. Thus, a survey of the heads of employment services in the regions of Russia, conducted in order to determine the directions for improving the system of payment of unemployment benefits, showed the following (Fig. 1). The overwhelming majority of heads of employment services (60 people) to propose strictly link the amount and periods of payment of benefits to the activity of citizens for employment. The second most of important proposal is related with implementation of the institution of unemployment insurance system. The experience of the OECD countries shows that in addition to the state, business and citizens participate in financing programs in 
the labour market through the unemployment insurance system, which fundamentally distinguishes this approach from the state employment policy in the Russian Federation [8].

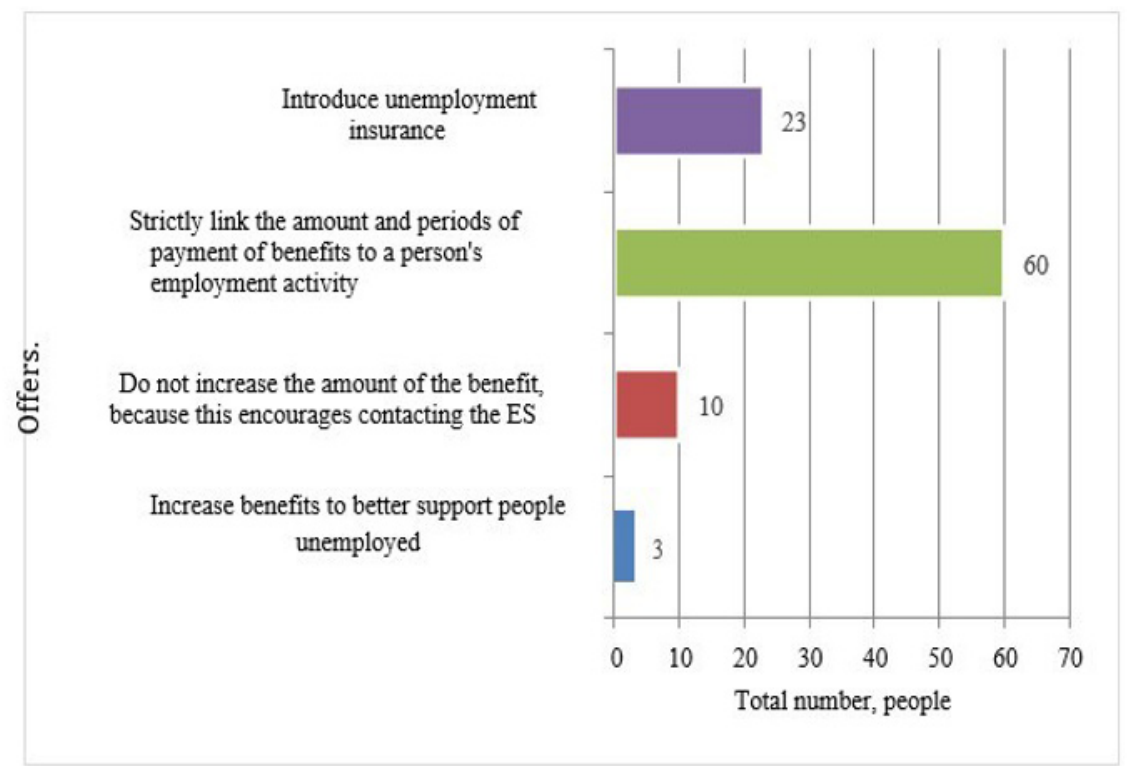

Fig. 1. Results of a survey of heads of employment services of Russian regions

Source: compiled by the author.

\section{Conclusion}

The results of the analysis showed that the implementation of an active policy of employment of the population requires improving the organization of work with redundant personnel. The authors proposed directions for the development of additional measures of labour mobility of redundant employees and providing the region with greater flexibility in the implementation of such programs. An assessment of the comprehensive effectiveness of an active employment policy should base on the indicators (indicators) of the state program of the Russian Federation "Promotion of employment of the population".

Currently, the socio - economic preconditions are ripe for changing the model of calculating and paying unemployment benefits. At the same time, the incentives to find a job should be significantly higher than the incentives to hide the income that can potentially obtained in the informal sector. A significant drawback of the existing mechanism of social support for laid off employees is that often the efforts of employment services to find jobs for citizens who have difficulties in finding a job are brought to naught in connection with the guaranteed measures of social support. It is necessary to take a comprehensive look at the whole range of support measures and guarantees for citizens who have difficulties in finding a job, from the point of view of their effectiveness.

It seems expedient to continue scientific and practical research of the problem both from the point of view of finding ways to maximize the integration of solutions carried out in this area, and from the point of view of predicting their results and distant socio-economic consequences. In-depth consideration also requires a search for ways to strengthen the social responsibility of managers at all levels of management for the consequences of decisions taken in the field of sustainable development, prevention of unjustified layoffs 
and support for laid-off workers and unemployed citizens.

\section{References}

1. Statistical Bulletin, Results of a sample survey of the labour force. II quarter 2021 (2021)

2. Yu. G. Odegov, L. S. Babynina, Monitoring of Public Opinion:Economic and Social Changes, 4 (2018)

3. L.V. Kartashova, Vestnik of the Plekhanov Russian University of Economics, 4 (2020)

4. Monitoring and assessing the quality and availability of public services in the field of promoting employment of the population, https://mintrud.gov.ru/

5. Draft Federal Law "On Amendments being made to the Law of the Russian Federation" On Employment of the Population in the Russian Federation", https://regulation.gov.ru/

6. E. I. Andreeva, D. G. Bychkov. Scientific Research Financial Institute. Financial j., 6(34) (2016)

7. V. N. Bobkov, N. V. Loktyuhina, M. V. Simonova, I. A. Shichkin, Advances in Intelligent Systems and Computing, 908 (2020)

8. Unemployment in Russia and foreign countries during the crisis. Social bulletin (2015) 